\title{
La creación artística anarquista en la ciudad de Buenos Aires (1900-1930)
}

\section{The Anarchist Artistic Creation in the City of Buenos Aires (1900-1930)}

\author{
María Fernanda de la Rosa \\ Facultad de Ciencias Sociales, Universidad Católica Argentina. \\ Buenos Aires, Argentina. \\ maria_delarosa@uca.edu.ar
}

\section{Resumen}

El arte tuvo siempre un lugar destacado dentro del universo libertario debido a que sus producciones fueron instrumentos de propaganda con una marcada finalidad ideológica. La heterogeneidad de estas producciones de arte en el anarquismo argentino produjo permanentes discusiones, conflictos y contradicciones. Este artículo reconstruye las características del arte ácrata en la ciudad de Buenos Aires entre los años 1900-1930. Estudia los textos doctrinarios de los principales teóricos y la manera en la que influyeron en los artistas locales. Consiste en un ejercicio de articulación entre las producciones locales, los artículos periodísticos y de revistas especializadas para habilitar un enfoque sobre los principios estéticos que delinearon. Se concluye que pese a su férreo internacionalismo y exclusión de las realidades nacionales, el arte libertario argentino tuvo un fuerte componente local entre artistas y militantes.

Palabras clave: Argentina, anarquismo, arte, estética.

\begin{abstract}
Art had always a prominent place in libertarian universe because the productions were advertising's instruments that carried a marked ideological purpose. This article reconstructs the characteristics of anarchist art in Buenos Aires between 1900 and 1930. It studies the doctrinal texts of the main theorists and the way in which they influenced the local artists, as well as the articulation between local productions, newspaper articles and specialized art magazines, in order to address the aesthetic values that delineate these productions. It concludes that, although anarchism preferred to exclude national realities due to its strong internationalism, argentine libertarian art had a strong local component that does not deny the libertarian anchorage of those artists and militants.
\end{abstract}

Keywords: Argentine, anarchist, art, esthetic. 


\section{Introducción}

La estética anarquista surge de la reflexión prospectiva de los fundadores del pensamiento anarquista [...], refleja el pluralismo fecundo de las diferentes corrientes del pensamiento libertario.

La estética anarquista, Reszler

"El arte como todo lo que existe, es vida, y la vida tiene que reflejarse en el arte". Esta frase, publicada en el periódico español Acracia en el año 1886, hace referencia a uno de los pocos ejes que vertebraron la estética libertaria: la creación artística entendida como la supresión de los elementos que distanciaran el arte de la vida (cit. en Álvarez 80). Antes bien, el artista deseaba transformarlos en una unidad dentro de la responsabilidad de cada ser humano. Ambas realidades se encontraban entre sí a partir de los fundamentos que sostenía la doctrina anarquista y debían constituirse en un instrumento perfecto no solo para mejorar la realidad del trabajador sino que también para construir una sociedad nueva. De este modo, las obras de arte se acercaban a la perfección cuanto más profunda era la verdad que transmitían en su contenido:

$\mathrm{El}$ arte es demasiado atrevido y autosuficiente [...] porque no tiene responsabilidades por la vida, la cual, por supuesto, no puede seguir a un arte semejante [...]. Entre ambos no hay unidad, y penetración mutua interior en la unidad de la personalidad. ¿Qué es lo que garantiza un nexo interno entre los elementos de una personalidad? Solamente la unidad responsable. Yo debo responder con mi vida por aquello que he vivido y comprendido en el arte, para que lo que he comprendido no permanezca sin acción en la vida [...]. El arte y la vida no son lo mismo, pero deben convertirse en mí en algo unitario, dentro de la unidad de mi responsabilidad (Bajtin 13-4).

En efecto, al anhelar la unión del arte y la vida propuesta por Bajtín, el artista debía mostrar la realidad que rodeaba al hombre aun cuando esta habitase en las zonas más oscuras de la sociedad, pues únicamente en la verdad de la vida el arte encontraba su escenario.

Resulta imposible comprender la estética del arte libertario sin entender los principios sobre los que se asentó su ideología. Heredero de la filosofía de la Ilustración y de la Revolución Francesa, el anarquismo constituyó la oposición frente a todo principio de autoridad como su pilar doctrinario más sólido, que vio encarnado en el capitalismo, la religión y el Estado. El sistema estatal, en tanto generador de vínculos opresivos, fue enjuiciado por partida doble. Por una parte, era considerado responsable de la división de la sociedad entre gobernados y gobernantes, explotados y oprimidos. Por otra parte, porque supuso la representación del poder político permanente e ins- 
tituido, así como también la expresión de los intereses de cierta clase social. De esta manera, la militancia ácrata se desarrolló dentro de un marco caracterizado por la oposición a la organización de un partido político, por un dinamismo constante y por la vocación internacionalista. Consecuencia especialmente de esta última variable fue la heterogeneidad, que se transformó en uno de los rasgos principales del movimiento anarquista argentino debido a los diversos grupos de inmigrantes - cada cual con su experiencia propia dentro del accionar obrero- que día a día desembarcaban en el puerto de Buenos Aires. El resultado fue la conformación de un movimiento variado y poliforme, en el cual la discordancia y la polémica fueron sus notas características:

Las incontables notas tituladas "nosotros los anarquistas", "nuestros propósitos" o "por que somos anarquistas" con los que se suelen presentar los periódicos, expresan tanto una identidad en proceso de construcción como las diferencias que habitan el movimiento: las distinciones ideológicas (organizadores o individualistas), estratégicas (grados de intervención en la organización obrera) o coyunturales (apoyo u oposición a una línea editorial central) (Fernández Cordero 27).

La presente investigación se centra en la ciudad de Buenos Aires durante el período comprendido entre 1900 y 1930 . A principios del siglo xx, el movimiento ácrata estaba consolidado: contaba con una gran cantidad de órganos de prensa, asociaciones, bibliotecas y federaciones desde la cuales se difundía la teoría libertaria. Las décadas del veinte y del treinta no fueron décadas perdidas ni ausentes de conflictos sociales, sin nada que destacar, como sugirió la historiografía tradicional. Por el contrario, la edición de periódicos y libros, la publicación de revistas y suplementos culturales, la representación de obras teatrales, las exposiciones pictóricas, las reuniones literarias, entre otras actividades, refieren a un movimiento activo que no solo tenía una voz sino que también un discurso colmado de ideología y estrategias. El golpe del 6 de septiembre de 1930 puso fin al sistema democrático argentino. Tras la revolución se desató una ola de persecuciones que afectó tanto al anarquismo como al socialismo y al sindicalismo revolucionario: los locales obreros fueron clausurados, muchos militantes ácratas se exiliaron, los apresados fueron enviados a la cárcel y los extranjeros a su país de origen.

El anarquismo buscó por medio del arte y de la cultura combatir permanentemente el poder estatal. Por ello se considera que todas las producciones artísticas del período fueron instrumentos de propaganda con una marcada finalidad ideológica. A partir de esta premisa, y teniendo como marco un movimiento en el cual se dan citas innumerables voces que no logran interpretar un concepto monológicamente, se desprende la siguiente interrogante: ¿cuáles fueron los ejes estéticos sobre los que se vertebraron las producciones artísticas que tuvieron lugar en Buenos Aires? Sería muy complejo -sino imposible- hallar respuestas únicas a esta pregunta, dado que no existió un cuerpo conceptual exclusivo que orientase al artista sobre las reglas que 
debía seguir durante el proceso creativo. Por el contrario, el arte libertario constituyó un impulso creador dominado por la espontaneidad y por la imaginación, libres de toda coerción estética externa. De allí que estuviese implícito su rechazo a toda imposición estética formal.

\section{Antecedentes}

Las producciones artísticas anarquistas no estuvieron regidas por ninguna norma ni estilo y, precisamente, dicha ausencia fue una de las características más notables del arte libertario. Sin embargo, existieron ciertos textos que, sin marcar una línea estilística a seguir, se trasformaron en los materiales de lectura que circularon entre los poetas, músicos, pintores y dramaturgos. Por ejemplo, entre otras obras, tuvo una clara influencia ¿Qué es el arte?, de León Tolstoi; El principio del arte y su destino social, de Pierre-Joseph Proudhon; La moral anarquista y Palabras de un rebelde, de Pior Kropotkin y El Arte desde el punto de vista sociológico, de Jean-Marie Guyau.

A juicio de Tolstoi, era necesario que el arte brindara al trabajador un espacio de ocio y contemplación, frente a las arduas tareas que se realizan diariamente. De allí que todas las producciones artísticas debían para él destacarse por su impronta social. "El artista no busca la belleza sino la justicia", fue una de las frases repetida recurrentemente en periódicos y conferencias. Dentro de esta concepción de arte social, el artista cumplía con retratar al pueblo trabajador en todas sus dimensiones.

Para Proudhon, la finalidad última del arte era la justicia, y su objeto, el hombre. Por lo tanto, el artista debía descifrar, comprender e interpretar su realidad para poder representarla fielmente en sus textos o lienzos. No obstante, las producciones libertarias no debían ser disruptivas, ya que se consideraba un grave error desvalorizar el arte y su historia. Admirador de las obras medievales, no solo por su rol transmisoras del valor universal sino que también porque habían sido disfrutadas por el trabajador del mismo modo que el cortesano, las producciones artísticas para Proudhon significaban la transformación de lo colectivo realizada por el mismo sujeto colectivo. De allí que no fuese necesario realizar una ruptura tajante con el arte del pasado sino que debía ser contemplado a partir de un presente liberado de toda servidumbre. "Avanzar pero conservando", sostenía Proudhon, quien además proponía un "arte en situación" y definía las obras como productos de la historia (120). Para él, el arte cambió con el surgimiento de la sociedad capitalista burguesa y el Estado. Las obras dejaron de ser comprendidas por el pueblo cuando comenzaron a transmitir sentimientos ajenos a su interés para ocuparse de un mundo superfluo y lujoso, caracterizado por una belleza descarnada y carente de todo compromiso social. Desde ese entonces, el pueblo fue privado tanto de su capacidad de creación como de goce, y su única participación en el mundo artístico de allí en adelante fue como asalariado del arte oficial. Leemos en La Antorcha: “¡Pobre arte el que para brotar e incendiarse de belleza necesita de las 
prebendas oficiales! [...]. El capital y el Estado ahogan, aprisionan y mutilan las más fecundas manifestaciones de transformación social" (Torres 3). Frente a esta situación debía levantarse el artista comprometido, para así devolver al trabajador el arte que le había sido quitado.

Al igual que Proudhon, Kropotkin sostenía que el hombre aprendía del pasado y no del porvenir. De allí su admiración por el arte medieval, disfrutado por toda la sociedad, independientemente de la clase social. Influenciado por la realidad política y social de la Rusia zarista, fue el primero en referirse al compromiso del artista desde un concepto moderno. En sus escritos, el arte debía ser rebelde y, como tal, poseer un compromiso de luchar contra la opresión. Como consecuencia, el artista debía despertar el espíritu revolucionario de cada ser humano. De esta manera, exhortaba a los artistas:

Vosotros, poetas, pintores, escritores, músicos; si comprendéis vuestra verdadera misión y el exacto interés del arte mismo [...] poned vuestra pluma, vuestro lápiz, vuestro cincel y vuestras ideas al servicio de la revolución; presentad [...] la lucha heroica del pueblo contra sus opresores; encended el corazón de nuestra juventud con ese glorioso entusiasmo revolucionario [...]. Mostrad al pueblo qué triste es su vida actual, y hacedle tocar con la mano la causa de su desgracia (59-60).

En efecto, el escritor comprometido puede expresar cualquier conflicto social histórico cuando advierte un hecho de la realidad social que estremece tanto a su propia existencia como a la de los demás. Al asumir un compromiso ético para denunciar una realidad que considera injusta y dolorosa, su arte se transforma en un fin y en un medio reconstituyente de la humanidad ya que ética y estética se despliegan de manera unida y se vuelven indisociables. En este sentido, la obra de arte sería socialmente salvadora.

Si reorientamos la mirada hacia las producciones artísticas locales, encontramos que el anarquismo rioplatense enfatizó la cuestión social propia del arte libertario como reflejo de las aspiraciones y tendencias de la colectividad, así como también de su progreso científico e intelectual. En efecto, la lectura del artículo "El anarquismo y el arte", publicado en el periódico La Protesta, manifiesta que uno de los pocos denominadores comunes de la estética anarquista fue considerar el arte como un fenómeno social (Ghiraldo 1). Su dimensión solidaria permitía que el artista reprodujera fielmente todas las aristas de la vida del trabajador: desde la cotidianeidad familiar hasta las más violentas luchas sociales a las que debía enfrentarse. Transformada la cuestión social en uno de sus ejes principales, uno de los principales objetivos del arte libertario fue reconocer la capacidad intelectual de multitudes anónimas, y permitirles experimentar la amplia gama de sentimientos y sensaciones a través de las producciones artísticas. El arte libertario, comprometido y urgente, a la vez que denunciaba y anunciaba constituyó una experiencia para quien lo producía y quien lo observaba. La 
conciencia crítica le permitía al artista cuestionar situaciones contextuales, marcadas por la injusticia social. Del mismo modo que crear una obra implicaba un humanismo utópico, esta se convertía en un eslabón más para derrumbar la estructura política y económica imperante, y regresar al hombre al anárquico orden original.

Fue Jean-Marie Guyau en su texto El arte desde el punto de vista sociológico, quien explicó el objetivo ácrata de valorar la estética de una obra de acuerdo con el concepto de solidaridad que comportaba y transmitía. Esta faceta social suponía una participación colectiva, activa y solidaria, en oposición a la contemplación que proponía el arte burgués. En su obra La Estética del arte anarquista, André Reszler halla la génesis del arte libertario en la idea de hijo y padre de la libertad, y a partir de dicho eje comienza su interrogación. Parta él, lo esencial de la naturaleza del arte y su función social estriba en su estética pluralista, que permite reflejar las diversas corrientes que surgieron dentro del mismo movimiento. Una vez más estamos frente a la idea de una estética sin estilo único, desde la cual el teórico libertario rechaza todo tipo de determinismos políticos, sociales y económicos. El discurso que trasmitía el artista libertario ponía como centro de inquietud al trabajador y las circunstancias que lo rodeaban. El impulso creador en sus múltiples formas no solo reflejaba las diversas fuerzas sociales en marcha sino también posibilitaba la renovación estética de toda la humanidad. Frente a esta realidad, y bajo una clara influencia de los autores mencionados, se fueron delineando los principales y diversos postulados del arte libertario. ${ }^{1}$

Sin embargo, no todos los teóricos ácratas mostraron el mismo entusiasmo ante esta premisa. Bakunin, por ejemplo, consideraba que si bien el arte como fenómeno social tenía una clara función de denuncia, no lo concebía como un arte militante. Como hemos mencionado, la estética libertaria no es homogénea, más bien es reflejo de la pluralidad interna que genera la existencia de corrientes de pensamiento dentro del movimiento anarquista que oscilan entre dos antípodas: el individualismo, que celebra la potencia creadora de cada ser humano; y el colectivismo, que exalta la creación de la colectividad libertaria. La historia del arte libertario es la conjunción de esta doble tendencia -individual y colectiva - que coloca al pueblo trabajador como centro y destinatario de su discurso. Asimismo, el anarquismo hizo una defensa radical del individualismo, donde el arte constituyó su forma más intensa, como Sostiene Reszler:

El arte libre, anarquista, individualista, es un arma contra la tiranía. Arte es sinónimo de individualismo, y el individualismo es una fuerza que molesta y destruye. De ahí viene su valor inmenso [...]. El arte es la forma más intensa del individualismo que el mundo jamás haya conocido (102-3).

1 Para mayor información sobre este tema vea: Litvak, Musa Libertaria, La mirada Roja; Williams, Cultura y Sociedad; Stegmayer, Las palabras y las artes. 
Tampoco dentro del anarquismo local hubo una postura homogénea respecto del rol revolucionario del arte. A juicio del ideólogo Diego Abad de Santillán, si bien las producciones artísticas constituían un factor importante para cambiar la coyuntura del orden político, social y económico no eran agentes decisivos en la lucha revolucionaria sino realidades auxiliares. Los conceptos de justicia y libertad se expresaban en la lucha cotidiana más que en las diversas ramas del arte (4). En la misma línea Simplicio de la Fuente expresó en un artículo publicado en La Antorcha que el arte no comportaba un valor revolucionario. Era la educación en la teoría anarquista mediante la lectura de los textos doctrinarios la que fomentaba el espíritu de rebeldía en el trabajador, por tanto, el arte acompañaba en este proceso formativo como un saber secundario (3).

En efecto, cada ser humano debía actuar según los dictados de su propia voluntad y conciencia; la libertad individual fue tanto un derecho absoluto como un principio supremo. El individuo era la única realidad, sin ninguna verdad ni existencia social o ideal por encima de él. "Cada individuo tendría la plena y exclusiva soberanía de sí mismo”, afirmó Pietro Gori, lo cual no implicaba oponer el individuo a la sociedad sino que, desde su accionar individual basado en la autonomía soberana -marcada por la libertad y la igualdad-, se evolucionaba hacia la solidaridad que permitía la relación con el otro (236). Sin embargo, el hombre fue considerado como el ser más individual de la tierra, al tiempo que el más social. Únicamente dentro de la sociedad debía ejercitarse la plena libertad individual y comunitaria, guiada por el mismo orden que regía las leyes de la naturaleza.

\section{Postulados estéticos libertarios}

Uno de los ejes alrededor del cual se vertebró la doctrina ácrata, y que resulta fundamental al analizar su arte, fue el concepto de naturaleza en tanto estado primitivo y positivo de la historia de la humanidad. Al igual que la naturaleza humana signada por un cambio constante que marcaba el desarrollo y crecimiento del hombre, ninguna actividad artística podía aceptar la existencia de reglas inmutables. Lo natural estaba directamente relacionado con la definición del término anarquía, el que no era considerado como un sinónimo de caos sino como un orden natural ideal que permitía un devenir armónico entre las especies de la naturaleza, sin ninguna fuerza externa que lo condicionara.

La sociedad humana debía regirse por las mismas leyes que guiaban los fenómenos físicos, y que resultaban opuestas a las instituciones políticas, las que eran no solo antinaturales sino representantes de ese poder autoritario y arbitrario que les había conferido el pacto social propuesto por Jean-Jacques Rousseau. De esta manera, el término naturaleza como sinónimo de unidad y armonía se opuso al de civilización como sinónimo de degradación, explotación y destrucción: 
El arte $[\ldots]$ necesita para desarrollarse hombres ampliamente puros, enemigos de las torres ebúrneas; valientes, hombres que posean verdadera conciencia artística y puedan definir nítidamente la conciencia excelsa de Natura, madre creadora de todos los seres con quien debe el arte sostener indisolubles vínculos, pues, que ella, y jsolo ella debe ser el sublime maestro, porque lo es! (Rezzano 3).

El concepto de naturaleza estuvo presente en las diversas producciones artísticas, desde la elección del nombre de las publicaciones -Germen, Sembrando Ideas- o de una de las asociaciones culturales porteñas - "Arte y Natura" - hasta su utilización en la literatura. En efecto, la naturaleza prestó su vocabulario para construir metáforas que pudiesen expresar la cotidianeidad de la vida: "Como marchito tallo de azucena/ acaba tu nariz en la corola/ rosada de la boca de sirena/ sintió el acre perfume de la ola/ del lago donde príncipes ahogados/ echan su corazón al sol en lotos/ asoman en la flor sus ojos rojos" (Blanchs 7). O la lucha libertaria: "roja es la aurora/ negra es la tierra/ y el surco abierto/ parece el fleco/ de una bandera/ de mi bandera/ que es roja y negra/ como la aurora/ sobre una pena" (González 134).

Como ya hemos mencionado, al igual que la naturaleza humana, ninguna actividad artística podía aceptar la existencia de reglas inmutables. La estética no supuso para los teóricos libertarios enmarcar lo bello dentro de los horizontes de lo sensible sino que se hallaba ligada a diversos conceptos propios del movimiento, con los cuales se cruzaba para coincidir o polemizar de manera permanente. Una mirada del arte en su conjunto muestra una pluralidad que permite afirmar que los artistas libertarios no elaboraron una estética ni monolítica ni propia; su concepción de arte no fue normativa más bien depositó en sus manos un amplio abanico de estilos, de temas y de géneros de los cuales poder nutrirse.

Si bien la mayoría de las veces compartieron los cánones estéticos utilizados por el arte burgués, un denominador común que atravesó gran parte de sus producciones fue el valor social plasmado tanto en la responsabilidad social que asumió el artista como en las temáticas representadas cuando se manifestaban las creencias, aspiraciones y problemáticas de los trabajadores. Crear para todos implicaba pensar en todos. De este modo, a través de la comunión de emociones y sentimientos, las producciones artísticas debían transportar al ser humano a un plano emocional universal. En palabras de José Álvarez Junco, estamos frente a un "arte realista conectado en sus temas con la realidad social en la que surge [...] y al servicio de la emancipación humana”, que al anhelar la reivindicación de los marginados y de los oprimidos supone la existencia de una sensibilidad estética, vinculada de forma tácita con la ética del movimiento libertario (83).

Coincidimos con Jorge Majfud cuando plantea la existencia de una "estética de la ética” (21), que podría ser aplicada para el análisis de la estética libertari. En efecto, el escritor comprometido logra expresar cualquier conflicto social cuando advierte un hecho de la realidad social que estremece no solo su propia existencia sino que también la de los demás. 
Como consecuencia "la cultura [...] anarquista se constituye así formando parte de un imaginario antijerárquico que [actúa] como contrapeso individual o colectivo frente a la imaginación hegemónica" (Petra 4). Dentro de una línea interpretativa, en la cual la capacidad de goce era instintiva y la opresión atravesaba todos los aspectos de la vida humana, las producciones siempre debían suscitar en el espectador el espíritu de rebeldía. Esta idea aparece reflejada en la siguiente estrofa del tango anónimo Guerra a la gente burguesa, escuchado frecuentemente en las veladas libertarias: "Guerra a la gente burguesa/ sin distinción de color/ que chupa la sangre humana/ del pobre trabajador./ Mientras los unos revientan/ a fuerza de trabajar/ los otros se pasan la vida/ vagando sin cesar" (cit. en Campo 39).

Transformado en un eje esencial de la cuestión social, uno de los principales objetivos del arte libertario fue reconocer la capacidad intelectual de multitudes anónimas, y permitirles experimentar la amplia gama de sentimientos y sensaciones a través de las producciones artísticas. La conciencia crítica le permitía al artista cuestionar una situación que le era contextual y que estaba marcada por la injusticia social. Como ya hemos mencionado, fue Guyau quien desde el punto de vista sociológico explicó el objetivo ácrata de valorar la estética de una obra. Para él, el arte fue un fenómeno social que se erigía sobre tres pilares fundamentales: su origen, su fin y su esencia, que apuntaba a convertirse en la expresión superior de la sociabilidad y "producir una emoción estética puramente social":

Todas las artes, en el fondo, no son sino múltiples maneras de condensar la emoción individual para hacerla inmediatamente transmisible a otra persona, para hacerla de algún modo más sociable [...]. Existe, pues, en este caso, una unión, una sociedad de almas realizada y viviente ante mi vista, que me invita a formar yo mismo parte de ella, y en la que entro, en efecto, con todas las fuerzas de mi pensamiento y de mi corazón (49-51).

De esta manera, la verdadera finalidad del arte era transformarse en expresión de la vida, provocando diversas sensaciones y emociones en el espectador. Al artista se le asignó el rol de un agente social por su capacidad de retratar la realidad en todas sus dimensiones, es decir, de expresar la vida con sus miserias y con sus encantos. Así, el arte debía obrar por sugestión para poder transmitir sentimientos afines y comprensibles al espectador. Varios escritos libertarios recogieron en sus premisas aspectos relativos a la sociología del arte en torno a lo que las producciones debían mostrar en todas sus manifestaciones el sentir del grupo. El artista le ponía nombre, forma o música a los sentimientos experimentados por un espectador que era incapaz de hacerlo; fue su tarea plasmar el sufrimiento del trabajador en un cuadro, en una poesía, en un cuento, en una canción, en una obra de teatro o en un dibujo.

El germen del sentido estético comportaba un carácter universal porque estaba presente tanto en la elite como en el resto de los hombres, aunque no siempre estos supieran o pudieran desarrollarlo. De allí que la estética ácrata podría ser pensada 
-al decir de Marc Argenot- como la "estética del pueblo", pues no solo incentivaba la lucha por la emancipación del trabajador sino también transformaba al arte en un instrumento de lucha (99). Así fue plasmada por Alberto Ghiraldo en un artículo publicado en la revista libertaria Ideas y Figuras:

Venimos a dar batalla [...] porque es caso de dignidad intelectual esforzarse por abrir camino entre nosotros a una tendencia artística que está destinada a una larga y fecunda misión. Porque no podemos dejar de honrar una obra [...] que no pertenece $\tan$ solo a su autor sino a todos lo que nos empeñamos en dignificar la vida [...] Ideas y Figuras con su continua e inquebrantable línea de combate por el triunfo de la Belleza, de la Justicia y de la Libertad, se ha colocado muy por encima de cualquier sospecha y ha conquistado el derecho de decir en todo momento su verdad (1).

Esto refleja los ejes sobre los cuales se erigió el arte libertario en la ciudad de Buenos Aires, que recuperaremos a continuación. "Venimos a dar batalla", escribió el cronista a fin de otorgarle al artista un rol combativo. Bajo una clara influencia de Kropotkin, el arte debía ser puesto al servicio de la Revolución Social o de lo que él denomina "Idea" (Kropotkin 296). El arte libertario nacía, entonces, de la tensión permanente que el artista vivía en su lucha cotidiana frente a la autoridad que mientras lo degradaba permanentemente, lo impulsaba a levantar un espíritu de rebeldía.

Dentro de esta misma sintonía estaban Proudhon, que consideraba que un arte comprometido era un eslabón más en el camino a la revolución social; Tolstoi, para quien el artista debía conciliar su libertad individual con la causa del pueblo y Jean Grave, que veía en el arte el resultado de la ilimitada creatividad humana puesto al auxilio de la lucha social. Todos consideraban que era necesario impregnarse socialmente y preparar a los trabajadores para su porvenir libertario, convocando a un público hasta el momento desfavorecido. En este sentido, la estética anarquista en su rol de "guardiana del espíritu de ruptura" debía animar al hombre a liberarse del peso de la tradición para buscar nuevos caminos hacia un porvenir donde las manifestaciones artísticas, al salir de los cenáculos burgueses, cobrasen un valor real y comenzaran a ser disfrutadas por las clases hasta ahora marginadas (Reszler 136). Como expresión de la vida del pueblo, las producciones artísticas se acercaban a la perfección cuanto más profunda era la verdad que transmitía su contenido.

¿Cuál era esa la misión larga y fecunda a la que estaba destinada una obra de arte? Respondía Ghiraldo: “dignificar la vida”. En efecto, como mencionamos al comienzo de este artículo, el arte debía transformarse en un instrumento perfecto desde la reunión entre arte y vida para mejorar la realidad del trabajador y construir una sociedad nueva, erigida sobre el "triunfo de la Belleza, de la Justicia y de la Libertad". Dicha unión debía estar mediada por el pueblo, entendido como el colectivo que era fuente y fin de las obras de arte. La concepción de un arte transmisor de los principios de justicia y libertad prevaleció en todas las manifestaciones artísticas y culturales libertarias, más allá de la belleza que comportaban. 
Por último, Ghiraldo en el artículo extraído de la revista Ideas y Figuras reconocía el derecho de toda obra de arte a "decir su verdad". Ahora bien, ¿cuál era la verdad intrínseca -o las verdades- de las producciones artísticas libertarias? Si bien no existió una respuesta única para todas las ramas del saber, podemos afirmar que la verdad anarquista estuvo traspasada por diversas premisas de carácter político, pedagógico, propagandístico e ideológico sobre las se vertebró el mapa estético libertario. Estas realidades se cruzaron de manera indefectible y resultó imposible establecer fronteras claras o límites entre ellas. Incluso la obra más densa y oscura fue considerada, en palabras de Lucas Rubinich, "portadora potencial de una significación poderosa [...] porque actúa, interviene, desde un espacio privilegiado, en la difuminación de visiones del mundo" (11). Como consecuencia, el arte libertario estuvo en tensión permanente con el orden dominante.

\section{Producciones artísticas libertarias}

"La ideología está en todas partes, todo lenguaje es ideológico [...] la ideología no solo predice representaciones, sino también modelos de prácticas y comportamientos", afirma Marc Angenot (27). El discurso de una obra de arte abarca un amplio abanico de la realidad para operar sobre un público formado por seres concretos: lo que transmite y la manera en que lo hace no son realidades inocentes, por el contrario, están cargadas de un fuerte contenido ideológico. Las manifestaciones culturales son productos históricos, resultado de la interrelación que se da entre la estética y su contexto. De allí que posean una clara potencialidad política aunque su fin inmediato no sea esencialmente politizar.

En efecto, el anarquismo argentino produjo obras marcadas por una superposición entre la estética y la militancia política. Le correspondió al artista -como agente canalizador del mensaje libertario y denunciador del presente- conjugar ambas dimensiones. Si bien es cierto que algunos artistas buscan que sus producciones provoquen tensiones y conflictos, existen otros que lo hacen por omisión.

Un claro ejemplo de un texto plagado de simbologías y metáforas referidas al contexto político nacional es la pieza teatral Juan y Juana, escrita por el militante González Pacheco mientras permanecía detenido en la cárcel de Villa Devoto. La obra se estrenó el 4 de junio de 1931, nueve meses después del golpe de Estado del general José Félix Uriburu. El argumento giraba alrededor de la relación que mantenía el personaje principal, un cultivador y vendedor de flores, con su perro. Apoyado en el miedo y el terror que generaba el animal, amenazando permanentemente con atacar a cualquiera que no fuese su dueño, el protagonista manejaba la vida de su esposa Juana, la de los empleados de su jardín y la de los pocos que se animaban a visitarlos. Por lo tanto, a través de la figura del perro-tirano como metáfora, el autor denuncia el autoritarismo, el abuso de poder y la opresión que vivía la sociedad argentina bajo la 
dictadura militar uriburista. Susurra temerosa Juana, "hasta el guardián de la espada llamante tenemos aquí. ¡El nuestro es un perro! [...] claro porque no se despierte o porque no se enoje una tiene que hablar siempre en voz baja" (81). A partir de este recurso metafórico, Pacheco le advertía al espectador que el mismo temor cotidiano vivido en aquella casa se experimentaba en el país tanto en la vida pública como privada de los ciudadanos. Un amigo de la pareja, Miguel, eterno viajero y amante de la libertad, cuestiona el poder que tiene el animal. De manera inesperada lo mata frente al asombro de los peones y de la propia Juana. A través de este acto de justicia poética del final, el autor afirma, en boca de Miguel: "Ningún tirano es un hombre, son todos perros" (102-4). Pacheco perseguía la reflexión del público, para que este advirtiera que con la muerte del perro Miguel no solo había liberado a Juana sino que también había devuelto a los trabajadores la libertad y la dignidad pérdidas, desde el momento en que Juan y el animal se les habían impuesto.

De acuerdo con el análisis de Víctor Shklovski, el carácter estético libertario de un objeto está marcado por dos variables: la primera es la manera en que el público percibe el arte, el impacto que causa más allá de la intención con la cual fue concebido inicialmente; la segunda es que toda obra de arte ácrata debe ser un medio para pensar (cit. en Todorov 57). Paralelamente, el arte ácrata puede ser pensado desde la concepción dialógica de Bajtin:

Orientada hacia la respuesta de otro (de otros), hacia su respuesta comprensiva, que puede adoptar diversas formas: intención educadora con respecto a los lectores, propósito de convencimientos, comentarios críticos, influencia con respecto a los seguidores y epígonos, etc.; una obra determina las posturas de respuestas de los otros dentro de otras condiciones complejas de la comunicación discursiva de una cierta esfera cultural. Una obra es eslabón en la cadena de la comunicación discursiva [...]. La obra se relaciona con otras obras-enunciados: con aquellos a los que contesta y con aquellos que le contestan a ella (262).

De esta manera, el discurso artístico cruza diversos planos de la realidad social, así como también las redes ideológicas que teje en torno a la existencia de una obra de arte hacen que su presencia no resulte indiferente al poder político. Por el contrario, ejerce diversas influencias dentro de la sociedad desde su aprobación o bien desde su exclusión. Según la premisa de Bajtín, el discurso pone en diálogo al objeto (producción artística) con el hablante (autor o creador) y el destinatario (comunidad anarquista o filoanarquista). Este último toma una postura determinada al comprender el significado del mensaje: puede estar o no de acuerdo con lo que se transmite. Desde la perspectiva batjiniana la respuesta del oyente lo convierte en hablante. "Usted es artista, hace versos [...] y nosotros los cantamos. Es con los versos de ustedes entre los labios que vamos al porvenir", asegura uno de los personajes compuesto por González Pacheco en su drama teatral Hijos del pueblo (109). 
Paralelamente, es el concepto de otredad el que configura tanto al sujeto como al enunciado que -aun antes de formularse- ha sido elaborado y pensado por y para otro: interlocutores, destinatarios, receptores. Existe, por tanto, una interacción marcada por la respuesta del destinatario, "es esta simultaneidad [...] esta presencia desdoblada del destinatario [...] la que va a marcar uno de los diálogos más definitorios del dialogismo" (Arfuch 65). Dentro de este marco teórico, una obra de arte constituye un eslabón más en la cadena dialógica, donde cada discurso es permeable a las ideologías, teorías, visiones y tendencias de una época determinada; el mensaje que transmite -cargado de diversos propósitos pedagógicos, persuasivos, empáticos y críticos, entre otros- está ligado con un pasado determinado y busca producir, a través del destinatario, efectos en el futuro. Aseguraba Juan Más y Pi en las páginas de la revista Ideas y Figuras: "Cada una de las obras que nos han legado los viejos maestros equivale a la consagración de una lucha. Y en cada una de ellas recibimos el aliento vigorizado de todos los entusiasmos que nos impelen a ir cada vez más lejos, cada vez más alto" (3).

A su vez, al relacionarse con otras "obras-enunciados" el mensaje elabora, reclama y demanda la respuesta del otro; para Bajtín se entabla de esta manera un cruce de diálogos afines, contemporizadores y conflictivos, producto de tensiones asimétricas. El discurso libertario se sitúa a la perfección en este análisis, donde "todo enunciado convocaba a la multiplicidad" y establece una relación entre emisores y receptores, generando una polifonía dinámica y multilateral, en un diálogo cargado de disputas y contradicciones (Arfuch 65). En su artículo "Un llamado a la concordia anarquista", la militante Juana Rouco se quejaba de la multiplicidad de voces que refiere el autor ruso: "el pasionismo [...] es hoy una regla general en todos los anarquistas. Los unos son 'Antorchistas', los otros 'Protestitas'. Y a los que no somos ni uno ni lo otro, también nos insultan" (1).

En 1913, bajo el trasfondo de una corriente profundamente dividida, Ghiraldo escribió su pieza teatral Columna de Fuego. El disparador era un conflicto gremial suscitado entre los trabajadores portuarios. El protagonista es un activista libertario perteneciente a la Federación Obrera Regional Argentina -en adelante, FORA-. Su contrafigura, un viejo militante activo de la asociación, toma la decisión de retornar al trabajo, aun a costa de traicionar la huelga. En un claro paralelo con la realidad por la cual atravesaba el movimiento, el autor expuso los motivos por los cuales dos fuerzas obreras destinadas a marchar juntas se dividen en corrientes opuestas, de modo que luchan entre sí, en lugar de formar un frente único contra el enemigo común. Desde la voz uno de los soldados encargados de reprimir la huelga, el autor insistía en la urgencia que requería la unificación del movimiento obrero. "Es triste que entre ellos mismos no se entiendan. Se ha dicho: ¡a no trabajar! Y ahí andan arrebatándose los puestos para conseguir un mendrugo" (149). Como bien observan Alderete y Manuli: "un Ghiraldo incansable levanta su vieja bandera: la unidad de la clase como requisito para vencer al Capital. Y lo hará de una manera 
contundente, mediante una estrategia ambiciosa que busca responder a las muchas necesidades del omento" (4).

Al igual que la obra de Ghiraldo, que pone de manifiesto la fricción y heterogeneidad del anarquismo, se enmarcó la pieza Hijos del Pueblo. Siguiendo un claro fin proselitista González Pacheco exhortaba desde el escenario teatral a la unidad sindical y a superar los conflictos internos que ahondaban las diferencias existentes entre los militantes. ${ }^{2}$ La pieza se estrenó en 1921, días antes de celebrarse en la ciudad de La Plata un congreso de la FORA. Por esta razón, la elección del nombre de la obra no fue casual, ya que la primera asociación que el espectador hacía cuando leía el programa era con el himno oficial ácrata, que aludía a la unidad: "Vindicación no hay que pedir;/ solo la unión la podrá exigir [...]/ Los corazones obreros que laten/ por nuestra causa, felices serán/ si entusiasmados y unidos combaten,/ de la victoria la palma obtendrán" (122).

La estética está íntimamente relacionada con la respuesta que provocará en el otro. Una obra de arte existe cuando ese otro da cuenta de ella y la convierte en arte, por medio de un proceso de interacción dialógica entre el creador y el contemplador. De lo contrario, es solo un "objeto físico creado por el hombre" (Voloshinov 173). Las respuestas que provoca el diálogo no son únicas ni últimas, todas tienen una parte de legitimidad y de verdad. Un autor comprometido no podía deslindar su arte del contexto que enmarcaba su creación; ese mundo con el que un texto, una canción, un dibujo se vinculaban cuasi naturalmente. Los conflictos sociales, económicos y políticos fueron para los artistas libertarios fuente de inspiración. Y en paralelo, debido a la interacción dialógica con sus propios contextos históricos, los mismos artistas transformaron los espacios sociales, los valores culturales y dialécticos que ellos mismos cuestionaban.

\section{Consideraciones finales}

Las producciones artísticas libertarias que tuvieron lugar en la ciudad de Buenos Aires en el período estudiado no fueron inocuas ni neutras sino que intervinieron en la cosmovisión del espectador. Por un lado, se buscaba instruir al público y obligarlo a reflexionar sobre una determinada realidad; por otro, se apelaba a su subjetividad y se lo incitaba a adoptar una determinada postura ideológica. En suma, se trataba de un arte que comportaba un claro propósito político y social, unido a un discurso pedagógico sumamente cuidado.

Es claro que la calidad de las producciones estaba dada por el carácter social que poseían y que paralelamente garantizaban su coherencia. En efecto, en la medida que

2 Para mayor información sobre este tema vea: Suriano, Auge y caída del anarquismo; López Trujillo y Anapios. 
una obra estaba vinculada con su problemática constituía un núcleo privilegiado de resistencia y de transformación de la vida. El arte local no escapó a la problemática que caracterizó al movimiento: los artistas reflejaron en sus obras la heterogeneidad y fricciones que generaron polifónico concierto de voces sumamente exacerbado en el movimiento anarquista argentino.

\section{Referencias}

Abad de Santillán, Diego. "Valoración de la literatura anarquista. El mundo de la libertad y el mundo de la autoridad”. La Protesta, 8 Abr. 1925, p. 4.

Aisemberg, Alicia y María de los Ángeles Sanz. "La antinomia inmigrante/criollo en el teatro de tesis social". Ed. Osvaldo Pellettieri. La inmigración italiana y teatro argentino. Buenos Aires, Galerna, 1999, pp. 51-66.

Alderete, Luciano y Martín Manuli. "La crisis y la revolución en el mundo actual. Análisis y perspectivas”. VIII Jornadas de Investigación Histórico Social: Razón y Revolución. Buenos Aires, Argentina, 9 de diciembre de 2009. Facultad de Filosofía y Letras Universidad de Buenos Aires, ponencia.

Álvarez Junco, José. La ideología política del anarquismo español. Madrid, Siglo XXI, 1991.

Anapios, Luciana. "El movimiento anarquista en Buenos Aires durante el período de entreguerras", Tesis de Doctorado en Historia. Universidad de Buenos Aires, 2012.

Angenot, Marc. El discurso social. Trad. Hilda H. García. Buenos Aires, Siglo xxi , 2010. Ansolabehere, Pablo. Literatura y anarquismo en Argentina (1879-1919). Buenos Aires, Beatriz Viterbo Editora, 2011.

Arfuch, Leonor, "Dialogismo". Carlos Altamirano, director. Términos críticos de la sociología de la cultura, Buenos Aires, Paidós, 2002, pp. 64-68.

Artaud, Antonin. El ombligo de los limbos. Trad. Juan Carlos Prieto Cané. Buenos Aires, Los libros de Orfeo, 1996.

Bajtin, Mijaíl. Estética de la creación verbal. Trad. Tatiana Bubnova. Buenos Aires, Siglo xxI, 2008.

Bakunin, Michael. Obras completas Vol. 2. Trad. Diego A. de Santillán. Madrid, La Piqueta, 1977.

Blanchs, Enrique. “Cabeza Pintada”. Ideas y Figuras. Revista Semanal de Crítica y Arte, 9 Agt. 1909, p. 7.

Camarero, Hernán. A la conquista de la clase obrera. Los comunistas y el mundo del trabajo en la Argentina, 1920-1935. Buenos Aires, Siglo xxi, 2007.

Campo, Javier. Las ideas libertaria y la cuestión social en el tango. Buenos Aires, Reconstruir, s/f.

De la Fuente, Simplicio. "La cultura no basta”. La Antorcha, 28 Agosto, 1925, p. 3. 
Fernández Cordero, Laura. Subjetividad, sexualidad y emancipación. Anarquistas en Argentina (1895-1925). Tesis de Doctorado en Sociología. Universidad Nacional de Buenos Aires, 2010.

Ghiraldo, Alberto. "La fiesta de Alma Gaucha. Ecos de la prensa". Ideas y Figuras. Revista Semanal de Crítica y Arte, 19 dic. 1911, p. 1.

---. "El anarquismo y el arte". La Protesta, 12 Jul. 1905, p. 5.

---. Teatro completo. Buenos Aires, La Obra, 1953.

González Pacheco, Rodolfo. Teatro Completo II, Buenos Aires, La Obra, 1953.

Gori, Pietro. Las bases morales y sociológicas del anarquismo: lo que queremos. Toulouse, CNT, s/f.

Guyau, Jean Marie. El arte desde el punto de vista sociológico. Trad. Ricardo Rubio. Madrid, Sáenz de Jubera, 1902.

Hofmann, Bert, y Tours Pere y Tietz Manfred, editores. El anarquismo español y sus tradiciones. Madrid, Vervuert-Iberoamericana, 1995.

Kropotkin, Piotr. “Trabajo cerebral y manual”. La Protesta, 1 Agt. 1903, pp. 3-4.

---."Trabajo cerebral y manual”. La Protesta, 8 Agt. 1903, p. 2.

---. Palabras de un rebelde. Barcelona, Centro Editorial Presa, 1908.

---. La moral anarquista. Trad. Frank Mintz. Madrid, Catarata, 2003.

Litvak, Lily. Musa libertaria. Arte literatura y vida cultural del anarquismo español (1880-1913). Barcelona, Antoni Bosch, 1981.

---. La mirada roja. Estética y arte del anarquismo español (1880-1913). Barcelona, Del Serbal, 1988.

López Trujillo, Fernando. Vidas en rojo y negro. Una historia del anarquismo en la Década Infame. Buenos Aires, Letra Libre, 2005.

Malosetti Costa, Laura y Marcela Gené, compuladoras. Impresiones porteñas. Imagen y palabra en la historia cultural de Buenos Aires. Buenos Aires, Edhasa, 2009.

Majfud, Jorge. "Roque Dalton: ética y estética de la liberación revolucionaria”. Razón y Revolución, $\mathrm{n}^{\circ}$ 17, 2007, pp. 21-26.

Mas y Pi, Juan. "La lucha en la Belleza”. Ideas y Figuras, 29 Jun. 1909, p. 3.

Petra, Adriana. "Anarquistas: cultura y lucha política en la Buenos Aires finisecular. El anarquismo como estilo de vida". Informe final del concurso: Culturas e identidades en América Latina y el Caribe. Programa Regional de Becas ClAcso, 2001, p. 4.

Reszler, Andrés. La estética anarquista. Trad. África Medina de Villegas. Buenos Aires, Fondo de Cultura Económica, 1974.

Rezzano, Luis. "El arte y la naturaleza”. La Protesta, 7 de Mzo. 1925, p. 3.

Rojo, Sara, "Teatro chileno y anarquismo (desde comienzos de siglo xx hasta el período dictatorial)". Aisthesis, ${ }^{\circ}$ 44, 2008, pp. 83-96.

Rouco, Juana. "Un llamado a la concordia anarquista". Nuestra Tribuna, 1 de Sep. 1924 , p. 1.

Rubinich, Lucas. "Apuntes sobre la politicidad del arte”. Ramona, revista de artes visuales, $\mathrm{n}^{\circ} 7,2007, \mathrm{p} .11$. 
Sáenz Hayes, Ricardo. "Almas de Crepúsculo". Ideas y Figuras. Revista Semanal de Crítica y Arte, 21 Sept. 1909, p. 5.

Stämpfli, Guillermo. "Hechos históricos y textos dramáticos: El campo santafesino y el drama rural, entre 1904 y 1920”. Memoria Americana, Cuadernos de Etnohistoria, ${ }^{\circ} 15,2007$, pp. 185-222.

Shklovski, Víctor. "El arte como artificio". Trad. Ana María Nethol. La teoría de la literatura de los formalistas rusos. Ed. Tzvetan Todorov. Buenos Aires, Siglo Xxi. 1970, pp. 55-70.

Suriano, Juan. Anarquistas. Cultura y Política Libertaria en Buenos Aires, 1890-1910. Buenos Aires, Manantial, 2001.

---. Auge y caída del anarquismo. Argentina, 1880-1930. Buenos Aires, Capital Intelectual, 2005.

Tolstoi, Lev. "Sobre la división del trabajo, la ciencia, el arte y sus profesores". La Protesta, 15 Agt. 1903, pp. 2-3.

---. "Sobre la división del trabajo, la ciencia, el arte y sus profesores". La Protesta, 12 Sept. 1903, pp. 2-3.

---. ¿Qué es el arte? Trad. Víctor Gallego. Madrid, Eunsa, 2007.

Torres, Jaime. "El arte y la merced estatal". La Antorcha, 31 de Jul. 1925, p. 3.

Proudhon, Pierre-Joseph. El principio del arte y su destino social. Emilio Gutiérrez de Quintanilla. Buenos Aires, Biblioteca Americana de Autores Selectos, 1896.

Voloshinov, Valentín. Freudismo. Un bosquejo crítico. Buenos Aires, Paidós, 1999.

Williams, Raymond. Cultura y Sociedad. Trad. Horacio Pons. Buenos Aires, Nueva Visión, 2001. 